\title{
Galectin 3 Level in Patients with Acute Coronary Syndrome and its Relation to Severity of Coronary Artery Disease
}

\author{
Ghada Mahmoud Soltan*, Niveen Ibrahim Samy, Aly Nasr Aly Mashal \\ Cardiology Department, Faculty of Medicine, Menoufia University, Menoufia, Egypt \\ Email: *soltanghada@yahoo.com
}

How to cite this paper: Soltan, G.M., Samy, N.I. and Mashal, A.N.A. (2020) Galectin 3 Level in Patients with Acute Coronary Syndrome and its Relation to Severity of Coronary Artery Disease. World Journal of Cardiovascular Diseases, 10, 784-795.

https://doi.org/10.4236/wjcd.2020.1012075

Received: May 6, 2020

Accepted: December 7, 2020

Published: December 10, 2020

Copyright $\odot 2020$ by author(s) and Scientific Research Publishing Inc. This work is licensed under the Creative Commons Attribution International License (CC BY 4.0).

http://creativecommons.org/licenses/by/4.0/

\begin{abstract}
Background: Acute coronary syndrome (ACS) is a very common cause of hospitalizations worldwide each year. Despite Troponin is considered the gold standard in diagnosis of ACS. Several molecules have been investigated to identify predictive biomarkers of diagnosis. Among these, Galectin-3 has emerged as a promising diagnostic biomarker of (ACS). We aimed to evaluate galectin-3 levels in patients with acute coronary syndrome (ACS) and its relation to severity of coronary artery disease. Methods: Seventy two patients with ACS who underwent primary percutaneous coronary intervention (PCI) and 20 age-matched healthy controls were enrolled in our study.The severity of coronary artery disease and the burden of atherosclerosis was assessed with Gensini score and with the number of affected vessels. Galectin-3 levels were measured on admission by using ELISA with a commercially kit. Result: The mean age of the observational case control study was $55.9 \pm 11.9$ and 68 patients $(73.9 \%)$ of the study were male. Median galectin-3 levels were significantly higher in ACS patients $(20.25 \mathrm{ng} / \mathrm{mL}[11.9$ - 39.0] vs. $8.9 \mathrm{ng} / \mathrm{mL}$ [4.6 24.0], $\mathrm{P}=0.001$ ). Patients were classified into three groups according to the number of involved vessels. Median galectin-3 levels were also significantly different among groups (one vessel: $18.9(12-35.2) \mathrm{ng} / \mathrm{mL}$, two vessels: 19 $(11.9$ - 35) $\mathrm{ng} / \mathrm{mL}$, three vessels $32(12-39) \mathrm{ng} / \mathrm{mL}, \mathrm{P}=0.007)$. There was a strong correlation between galectin- 3 levels and Gensini score $(\mathrm{r}=0.500, \mathrm{P}=$ 0.001). Conclusion: Galectin-3 levels were elevated in patients with ACS and there was a strong correlation between galectin-3 and severity of coronary artery disease.
\end{abstract}

\section{Keywords}

ACS, Atherosclerosis, Galectin 3, PCI, Gensini Score 


\section{Introduction}

Acute coronary syndrome (ACS) encompasses a spectrum of clinical disorders of myocardial ischemia or infarction, and still is the first cause of death in the world, especially in the first hours. Acute coronary syndrome (ACS) presents as unstable angina, non-ST segment elevation myocardial infarction (NSTEMI) or ST-segment elevation myocardial infarction (STEMI). There are various etiologies underpinning ACS, but the predominant disease mechanism is atherosclerosis, with the potential for subsequent plaque disruption leading to thrombosis and cessation of myocardial blood flow. Atherosclerosis is a progressive disease of plaque deposition, which consists of lipids, smooth muscle cells, and calcium within the layers of the blood vessel. It is thought to be triggered by the deposition of cholesterol-containing plasma lipoproteins in the subendothelium at points of altered flow hemodynamics, leading to inflammatory changes in endothelial cells [1].

If complete occlusion of the coronary blood supply occurs, this results in a STEMI, whereas NSTEMI results from a transient or incomplete obstruction of flow [2].

Percutaneous coronary intervention (PCI) is the most effective method to restore coronary perfusion in acute ST segment elevation myocardial infarction (STEMI), where coronary flow can be restored in $85 \%$ of patients [3].

Galectin-3 is a soluble B-galactoside-binding lectin that mediates different pathways of inflammation and fibrosis [4]. It is expressed by activated macrophages and regulates several inflammatory cells including lymphocytes, neutrophils, monocytes and mast cells [5]. Studies have shown that galectin-3 induces the migration of monocytes and macrophages, triggers antioxidant secretion from active phagocytic cells, promotes fibroblasts proliferation and increases collagen synthesis [6]. A genetic mutation in galectin-3 has been shown to impede these pathways causing inadequate phagocytosis and impaired immune response [7]. Those properties emphasize the pivotal role of galectin-3 in inflammation and fibrosis, motivating numerous studies evaluating the function of galectin-3 in cardiovascular diseases [8]. Although several studies have been conducted to assess the association of galectin-3 in heart failure and remodeling, less is known about the role of galectin-3 in coronary artery disease and in ACS. In this study, we aimed to evaluate the galectin-3 levels in patients with ACS and the relation of galectin- 3 with the severity of the coronary artery disease by gensini score and number of involved vessels.

\section{Methods}

\section{Study population:}

The study was conducted on 72 patients with acute coronary syndrome (ACS), presenting as ST-segment elevation myocardial infarction (STEMI) or non-ST segment elevation myocardial infarction (NSTENII) undergoing coronary angiography. 
And 20 healthy age and sex matched individuals, (control group) presented to National Heart Institute and menoufia university hospitals during the period from march 2018 till September 2018 and The diagnosis of acute coronary syndrome was based on the criteria of ESC/ACC/AHA by ST elevated myocardial infarction diagnosis was based on typical chest pain and new ST segment elevation in 2 or more contiguous leads of at least $0.25 \mathrm{mV}$ in men below the age of 40 years old, at least $0.2 \mathrm{mV}$ in men over the age of 40 years old, or at least $0.15 \mathrm{mV}$ in women measured at the J point in leads V2 \& V3 0r at least $0.1 \mathrm{mV}$ in other leads or new onset of complete left bundle-branch block. And Non-ST elevated myocardial infarction was based on elevated cardiac enzymes with typical chest pain and/or electrocardiographic changes suggestive of myocardial ischemia.

Information regarding risk factors including age, gender, Diabetes mellitus, hypertension, hyperlipidemia, and smoking status was obtained. Hypertension was defined as blood Pressure $>140 / 90 \mathrm{mmHg}$ on $>2$ occasions during office measurements or use of antihypertensive treatment. Diabetes mellitus was defined as fasting blood glucose $>126 \mathrm{mg} / \mathrm{dL}$ or use of antidiabetic treatment. Hyperlipidemia was considered to be present in patients with fasting total cholesterol $\geq 200 \mathrm{mg} / \mathrm{dL}$ or triglyceride $\geq 150 \mathrm{mg} / \mathrm{dL}$.

The severity of the coronary artery disease was assessed by Gensini score and with the number of involved vessels. Transthoracic echocardiography was performed for each patient immediately after admission to hospital using a commercially available machine (PHILIPS HD7 XE) with a $3.5-\mathrm{MHz}$ transducer. And informed consent was obtained from each patient.

Laboratory.

Venous blood samples were obtained immediately after admission. CBC, CK, $\mathrm{CK} \mathrm{MB}$, troponin I, Plasma glucose, creatinine, urea, was measured by using standard methods.

Blood samples were centrifuged after 30 minutes of sampling. Serum was isolated and stored at $-20^{\circ} \mathrm{C}$ for galectin-3 measurement. After collecting all serum samples, galectin-3 was measured by Solid phase enzyme linked immunosorbent assay (ELISA) with a commercially available kit at menoufia university hospital, Egypt.

Statistical Analysis: Data were analyzed using Statistical Program for Statistical Program for Social Science (SPSS) version 23.0 for windows (SPSS Inc., Chicago, IL, USA) and NCSS 12 for windows (NCSS LCC., Kaysville, UT, USA). Quantitative data were expressed as mean \pm standard deviation (SD). Qualitative data were expressed as frequency and percentage.

\section{Results}

72 patients and 20 controls were studied to test the hypothesis that elevated the galectin-3 levels in patients with ACS and its association with the severity of the coronary artery disease.

The mean age of the patients was $56.3 \pm 12.7$ years and $51.6 \pm 7.7$ years in 
controls. The baseline demographics, risk factors and laboratory findings of the enrolled subjects are summarized in Table 1 below.

As regard type of STEMI (by ECG), there were 44 of patients of group I with anterior MI, 23 patients with inferior MI and 5 patients with lateral.

As regard galectin 3, the median galectin 3 level of the patients was 20.25 (11.9 - 39.0) in patients group I. And 8.9 (4.6 - 24.8) in controls group II. The comparative study between the two groups shows a significant difference $(\mathrm{P}<0.001)$ (Figure 1) and summarized in Table 2.

ROC analysis showed that a galectin- 3 cut off value of $\geq 12.5 \mathrm{ng} / \mathrm{mL}$ predicted ACS with $88.9 \%$ sensitivity and $70 \%$ specificity $(\mathrm{P}<0.001)$ (Figure 2$)$.

Patients were classified into three groups according to the number of involved vessels. Median galectin-3 levels were showed significant difference among groups (one vessel: $18.9(12-35.2) \mathrm{ng} / \mathrm{mL}$, two vessels: $19(11.9-35) \mathrm{ng} / \mathrm{mL}$, three vessels $32(12-39) \mathrm{ng} / \mathrm{mL},(\mathrm{P}=0.007)$ (Figure 3$)$ and summarized in $\mathrm{Ta}$ ble 3 .

There was a strong correlation between galectin-3 levels and gensini score $(\mathrm{r}=$ $0.500, \mathrm{P}=0.001$ ) (Figure 4) and summarized in Table 4.

- Table 1. Comparison between the studied groups regarding the demographic data.

\begin{tabular}{|c|c|c|c|c|}
\hline Demographic data & ACS & Controls & Test & $\mathrm{P}$-value \\
\hline Count (\%) & $72(78.3 \%)$ & $20(21.7 \%)$ & & (Sig.) \\
\hline \multicolumn{5}{|l|}{ Age (years) } \\
\hline Mean \pm SD & $56.3 \pm 12.7$ & $51.6 \pm 7.7$ & $1.597 \bullet$ & 0.110 \\
\hline Median (Range) & $57(34-86)$ & $52(37-66)$ & & (NS) \\
\hline \multicolumn{5}{|l|}{ Gender } \\
\hline Male & $54(75 \%)$ & $14(70 \%)$ & $0.203 \ddagger$ & 0.652 \\
\hline Female & $18(25 \%)$ & $6(30 \%)$ & & (NS) \\
\hline \multicolumn{5}{|l|}{ Risk factors } \\
\hline \multirow[t]{2}{*}{ HTN } & $30(41.7 \%)$ & $10(50 \%)$ & $0.442 \ddagger$ & 0.506 \\
\hline & & & & (NS) \\
\hline \multirow[t]{2}{*}{$\mathrm{DM}$} & $33(45.8 \%)$ & $7(35 \%)$ & $0.747 \ddagger$ & 0.387 \\
\hline & & & & (NS) \\
\hline \multirow[t]{2}{*}{ Smoking } & $56(77.8 \%)$ & $12(60 \%)$ & $2.566 \ddagger$ & 0.109 \\
\hline & & & & (NS) \\
\hline \multirow[t]{2}{*}{ Dyslipidemia } & $9(12.5 \%)$ & $3(15 \%)$ & $0.086 \ddagger^{\mathrm{F}}$ & 0.719 \\
\hline & & & & (NS) \\
\hline \multirow[t]{2}{*}{ Family history of IHD } & $10(13.9 \%)$ & $3(15 \%)$ & $0.016 \ddagger^{\mathrm{F}}$ & 1.000 \\
\hline & & & & (NS) \\
\hline
\end{tabular}

- Mann Whitney U test. $\ddagger$ Chi-square test. $\ddagger^{\mathrm{F}}$ Fisher's Exact test. $\mathrm{P}<0.05$ is significant. Sig.: significance. 
Table 2. Comparison between the studied groups regarding the cardiac biomarkers.

\begin{tabular}{ccccc}
\hline Cardiac biomarkers & ACS & Controls & Test & P-value \\
\hline Count (\%) & $72(78.3 \%)$ & $20(21.7 \%)$ & & $($ Sig. $)$ \\
\hline Troponin & & & & \\
Negative & $7(9.7 \%)$ & $20(100 \%)$ & $61.523 \ddagger$ & $<0.001$ \\
Positive & $65(90.3 \%)$ & $0(0 \%)$ & & $(\mathrm{HS})$ \\
CK-total (IU/L) & & & & \\
Mean \pm SD & $725.2 \pm 778.1$ & $96.6 \pm 29.0$ & $5.759 \bullet$ & $<0.001$ \\
Median (Range) & $478(57-3242)$ & $96(54-156)$ & & $(\mathrm{HS})$ \\
CK-MB (IU/L) & & & & $<0.001$ \\
Mean \pm SD & $66.2 \pm 56.7$ & $16.8 \pm 3.4$ & $5.988 \bullet$ & $(\mathrm{HS})$ \\
Median (Range) & $40(16-333)$ & $16.5(11-23)$ & & $<0.001$ \\
Galectin-3 (ng/mL) & & & & $(\mathrm{HS})$ \\
Mean \pm SD & $22.7 \pm 8.1$ & $10.7 \pm 6.3$ & $5.251 \bullet$ & \\
Median (Range) & $20.25(11.9-39.0)$ & $8.9(4.6-24.8)$ & & \\
\hline
\end{tabular}

- Mann Whitney U test. $\ddagger$ Chi-square test. $\mathrm{P}<0.05$ is significant. Sig.: significance.

Table 3. Comparison between single, two and three vessel disease regarding galectin-3 level.

\begin{tabular}{cccccc}
\hline N. of vessel & One vessel & Two vessel & Three vessel & Test & P-value \\
\hline affected & disease & disease & disease & & (Sig.) \\
\hline Count (\%) & 29 & 27 & & & \\
& $(40.3 \%)$ & $(37.5 \%)$ & $(22.2 \%)$ & & \\
Galectin-3 (ng/mL) & & & & & \\
Mean \pm SD & $20.8 \pm 6.8$ & $20.8 \pm 6.7$ & $29.3 \pm 9.7$ & 10.016 & 0.007 \\
Median & 18.9 & 19 & 32 & $\mathrm{~K}$ & $(\mathrm{~S})$ \\
(Range) & $(12-35.2)$ & $(11.9-35)$ & $(12-39)$ & &
\end{tabular}

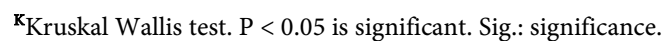

Table 4. The correlation analysis of galectin-3 and other variables within ACS group.

\begin{tabular}{ccc}
\hline & & Galectin-3 (ng/mL) \\
\hline Age (years) & Correlation Coefficient & 0.211 \\
Ejection fraction (\%) & Sig. (2-tailed) & 0.076 \\
& Correlation Coefficient & -0.199 \\
Wall motion score index (WMSI) & Sig. (2-tailed) & 0.094 \\
& Correlation Coefficient & 0.004 \\
Hemoglobin (g/dL) & Sig. (2-tailed) & 0.972 \\
& Correlation Coefficient & -0.057 \\
INR & Sig. (2-tailed) & 0.636 \\
& Correlation Coefficient & -0.066 \\
Creatinine (mg/dL) & Sig. (2-tailed) & 0.582 \\
& Correlation Coefficient & 0.077 \\
& Sig. (2-tailed) & 0.522 \\
\hline
\end{tabular}




\section{Continued}

\begin{tabular}{|c|c|c|}
\hline \multirow[t]{2}{*}{ CK-total (IU/L) } & Correlation Coefficient & 0.012 \\
\hline & Sig. (2-tailed) & 0.923 \\
\hline \multirow[t]{2}{*}{ CK-MB (IU/L) } & Correlation Coefficient & -0.039 \\
\hline & Sig. (2-tailed) & 0.742 \\
\hline \multirow[t]{2}{*}{ Gensini score } & Correlation Coefficient & 0.500 \\
\hline & Sig. (2-tailed) & $<0.001$ \\
\hline
\end{tabular}

$\mathrm{P}<0.05$ is significant. Sig.: significance.

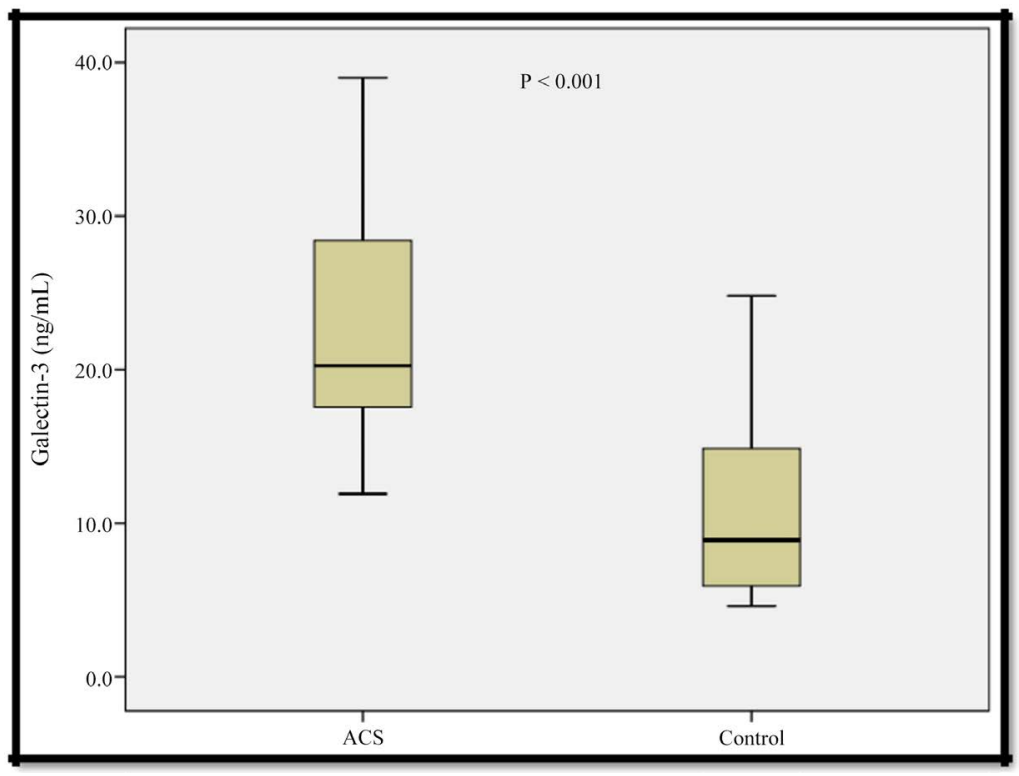

Figure 1. Galectin-3 levels in both group.

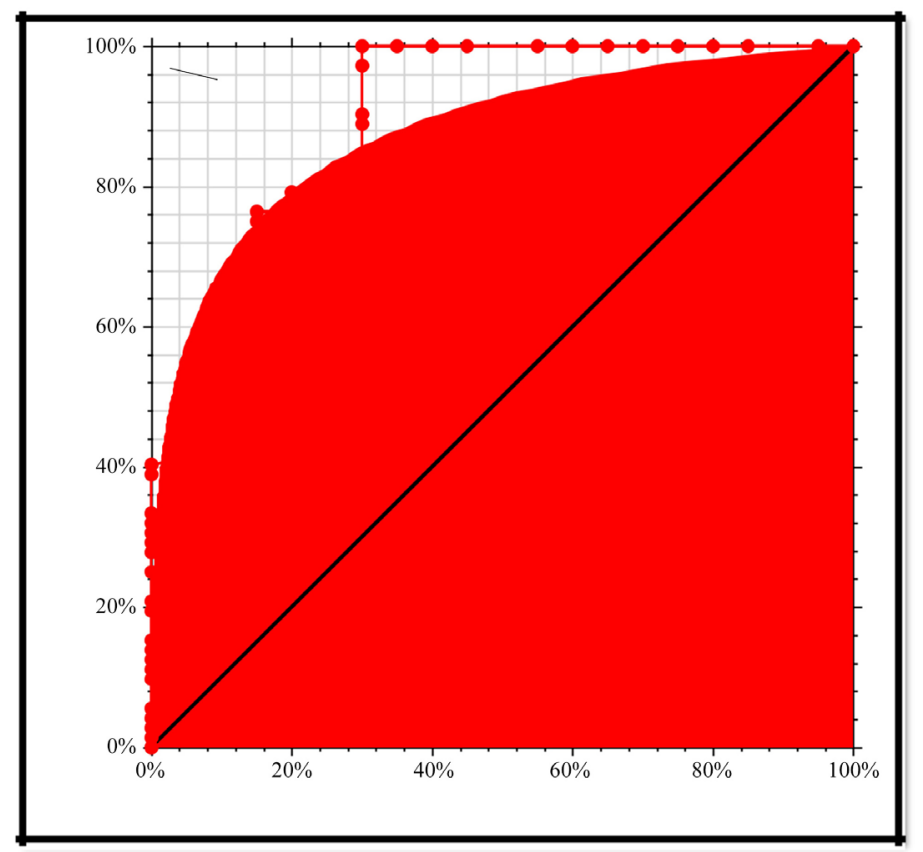

Figure 2. Roc of glectin 3 in acute coronary syndrome. 


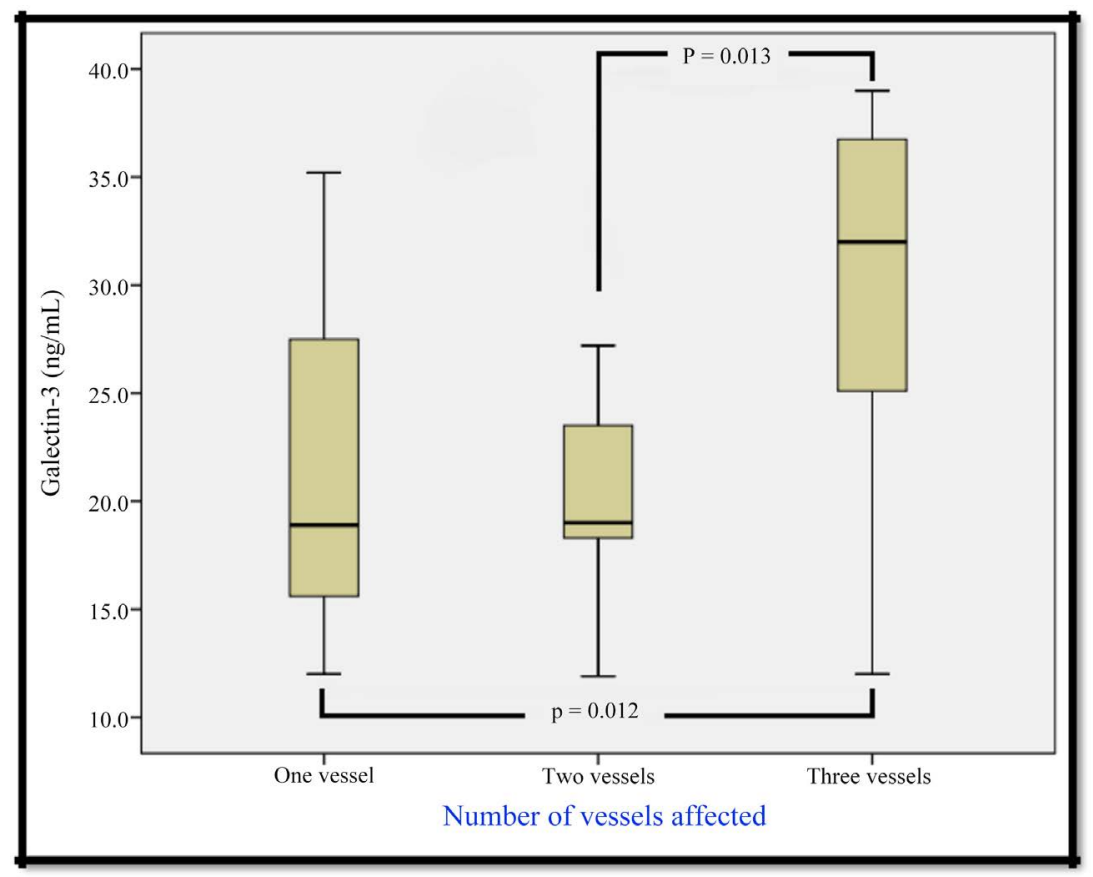

Figure 3. Comparison between single, two and three vessel disease regarding galectin-3 level.

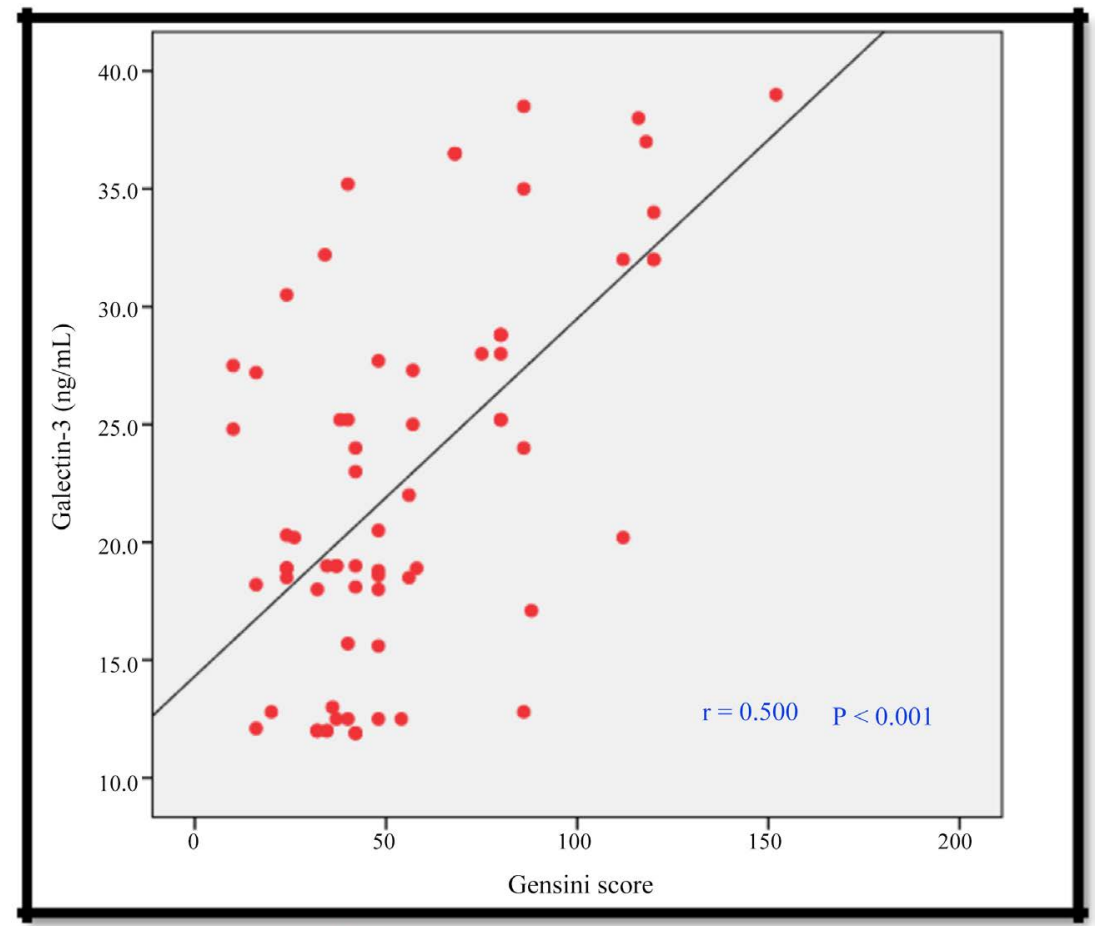

Figure 4. The correlation analysis of galectin-3 and gensini score within ACS group.

\section{Discussion}

Galectins are lectins with $\beta$-galactoside-binding domains. According to chemical structure, they are divided into 3 types: prototype, chimera and tandem. Among 
the fifteen Galectins identified up to now, Galcten-3 is the only one belonging to the chimera type. It is normally expressed in several cytotypes, e.g. in endothelial cells, epithelial cells, activated microglia, inflammatory cells (mainly macrophages) and various tissues, including spleen, stomach, colon, liver, kidney, heart, uterus, ovary and pancreas [9]. Galcten-3 is a highly versatile protein involved in various physiological and pathological processes, as cell growth, angiogenesis, cancerogenesis, and inflammation. Particularly, it has a pivotal role in triggering inflammation in a wide range of acute as well as chronic conditions, including neurological degeneration, autoimmune diseases, atherosclerosis and heart failure, diabetes, wound repair, response to infection, lung, kidney and liver disease, and many other conditions [10]. Under certain conditions, as ischemic injury, Galcten-3 is over-expressed in attempt to regulate and maintain cell survival [11] Finally, Galcten-3 is involved in adverse cardiac remodeling and fibrosis; particularly, it has been shown that Gal-3 induces cardiac fibroblasts to proliferate and deposit type I collagen in the myocardium [12] [13].

In our study, the mean age of the patients was $56.3 \pm 12.7$ years and $51.6 \pm 7.7$ years in controls. We found elevated galectin-3 levels in patients with acute coronary syndrome as compared to control group. The median galectin 3 level of the patients was 20.25 (11.9 - 39.0) in patients group I .And 8.9 (4.6 24.8) in controls group II. The comparative study between the two groups shows a significant difference $(P=0.001)$. These results were in agreement with the results reported by E. Gucuk Ipeka et al., study [14].

We observed that galectin 3 in acute coronary syndrome has high sensitivity compared to E. Gucuk Ipek a et al. [14] and this result may refer to a large number of patients compared to that study which has nineteen patients with acute coronary syndrome and seventeen age matched controls while we have seventy two patients with acute coronary syndrome and twenty age matched control. Also previous studies also reported similar findings as Falcone C. et al. [15] and also Menini S. et al. [16].

Papaspyridonos et al. [17] Demonstrated elevated galectin-3 expression in unstable atherosclerotic plaques. The expression was positively correlated with age and plaque size, suggesting the role of galectin- 3 in progression of the atherogenesis in chronic phase.

In our study we found There was a strong correlation between galectin-3 levels and gensini score $(r=0.500, P=0.001)$.

These results confirms the role of galectin-3 in chronic inflammation and atherogenesis and were in agreement with (Menini S. et al.; E. Gucuk Ipek a et al.; and Aksan G et al.; [14] [16], Gucuk Ipeka et al. and colleagues investigated the link between galectin 3 and severity of coronary artery disease and reported that galectin-3 have a significant positive correlation with Gensini score $(\mathrm{r}=$ $0.625, \mathrm{P}=0.00$ ).

The results of the present study are also concordent with Aksan et al. who reported that in the correlation analysis, serum galectin-3 showed significant correlation with the Gensini score $(\mathrm{r}=0.715, \mathrm{P}<0.001)$. 
The association between Gensini scores and galectin-3 suggests that galectin- 3 may predict the severity of the coronary artery disease in clinical practice, and may become an additional tool in identifying high-risk patients. These results were in agreement with the results reported by E. Gucuk Ipek a et al., [14].

Also, in our study we found Patients were classified into three groups according to the number of involved vessels. Median galectin-3 levels were significant difference among groups (one vessel: 18.9 (12 - 35.2) ng/mL, two vessels: 19 (11.9 - 35) ng/mL, three vessels 32 (12 - 39) ng/mL, $\mathrm{P}=0.007)$.

These results were not in agreement with the results reported by E. Gucuk Ipek a et al., [14] and this may be attributed to a large number of patients in our study and difference in test sensitivity compared to previous study.

As regard $\mathrm{EF} \%$, the mean ejection fraction of the patients was $50.4 \pm 10.7$ in group I and $61.3 \pm 4.6$ in controls group II. The comparative study between the two groups shows significant difference.

We observed that patients with impaired ejection fraction tended to have higher levels of galectin-3 but that difference did not reach statistical significance.

These results were not in agreement with the results reported by E. Gucuk Ipek a et al., [14] which showed the reverse correlation between galectin 3 level and ejection fraction in patients with acute coronary syndrome with statistical significance and this may be attributed to early presentation of patients to our tertiary heart center where all investigations were done as fast as possible which was not enough period to impaired the global function.

We observed also that the mean creatinine level of the patients was $1.03 \pm 0.35$ in group I. And $0.78 \pm 0.12$ in controls group II. The comparative study between the two groups shows a difference but that difference did not reach statistical significance.

But these results are disconcordant with E. Gucuk Ipek a et al., [14] which reported that higher plasma galectin-3 levels were found to be associated with impaired renal function and poor survival rates

In Comparison to the previous researchs in the literature, we observed the difference of galectin-3 concentrations in our case-control study with previous study Falcone C et al., [15] and E. Gucuk Ipek a et al., [14] in which the researchers analyzed galectin-3 with a different commercial ELISA kit and also we calculate the galectin 3 in plasma instead of serum.

One of the most serious limitations in our study was the lack of follow up which interfere with documentation of complications and outcomes and kinetics of galectin-3 levels during hospital stay.

These limitations were overcame by previous study Milner et al., E. Gucuk Ipek a et al., and Falcone C et al., [14] [15] which reported that Gal-3 levels change following a STEMI according to timing of reperfusion. They found Gal-3 to be elevated in patients immediately after STEMI and significantly decreased within 24 hour proportionally with increasing time since reperfusion. 
Some Authors evaluated the potential role of Galctin-3 as a predictive marker of mortality, HF, atrial fibrillation (AF) and re-infarction in ACS patients [18] [19] [20] [21] [22].

\section{Conclusion}

According to our findings, elevated galectin-3 in patients had acute coronary syndrome and there was strong correlation between galectin 3 level and severity of coronary artery disease which reflected by gensini score and number of involved vessels, so galectin 3 may become a promising biomarker for diagnosis of coronary artery disease and provide complementary information for assessment of severity of coronary artery.

\section{Acknowledgements}

Human galectin 3 ELISA kit Catalog No:E0497h supported by authors credit.

\section{Conflicts of Interest}

The authors declare no conflicts of interest regarding the publication of this paper.

\section{References}

[1] Tabas, I., García-Cardeña, G. and Owens, G.K. (2015) Recent Insights into the Cellular Biology of Atherosclerosis. Journal of Cell Biology, 209, 13-22. https://doi.org/10.1083/jcb.201412052

[2] Ellis, S.G., Tendera, M., de Belder, M.A., van Boven, A.J., Widimsky, P., Janssens, L., Andersen, H.R., Betriu, A., Savonitto, S., Adamus, J., Peruga, J.Z. and Kosmider, M., et al. (2015) Facilitated PCI in Patients with ST-Segment Elevation Myocardial Infarction. The New England Journal of Medicine, 358, 2205-2217. https://doi.org/10.1056/NEJMoa0706816

[3] Libby, P. (2013) Mechanisms of Acute Coronary Syndromes and Their Implications for Therapy. The New England Journal of Medicine, 368, 2004-2013. https://doi.org/10.1056/NEJMra1216063

[4] Sano, H., Hsu, D.K., Yu, L., Apgar, J.R., Kuwabara, I., Yamanaka, T., et al. (2000) Human Galectin-3 Is a Novel Chemoattractant for Monocytes and Macrophages. The Journal of Immunology, 165, 2156-2164. https://doi.org/10.4049/jimmunol.165.4.2156

[5] Yamaoka, A., Kuwabara, I., Frigeri, L.G. and Liu, F.A. (1995) Human Lectin, Galectin3 (Epsilon bp/Mac-2), Stimulates Superoxide Production by Neutrophils. The Journal of Immunology, 154, 3479-3487.

[6] Hsu, D.K., Yang, R.Y., Pan, Z., Yu, L., Salomon, D.R., Fung-Leung, W.P., et al. (2000) Targeted Disruption of the Galectin-3 Gene Results in Attenuated Peritoneal Inflammatory Responses. The American Journal of Pathology, 156, 1073-1083. https://doi.org/10.1016/S0002-9440(10)64975-9

[7] Anand, I.S., Rector, T.S., Kuskowski, M., Adourian, A., Muntendam, P. and Cohn, J.N. (2013) Baseline and Serial Measurements of Galectin-3 in Patients with Heart Failure: Relationship to Prognosis and Effect of Treatment with Valsartan in the Val-HeFT. European Journal of Heart Failure, 15, 511-518. 
https://doi.org/10.1093/eurjhf/hfs205

[8] Gullestad, L., Ueland, T., Kjekshus, J., Nymo, S.H., Hulthe, J., Muntendam, P., et al. (2012) The Predictive Value of Galectin-3 for Mortality and Cardiovascular Events in the Controlled Rosuvastatin Multinational Trial in Heart Failure (CORONA). American Heart Journal, 164, 878-883. https://doi.org/10.1016/j.ahj.2012.08.021

[9] Dumic, J., Dabelic, S. and Flögel, M. (2006) Galectin-3. An Open-Ended Story. Biochimica et Biophysica Acta (BBA) - General Subjects, 1760, 616-635. https://doi.org/10.1016/j.bbagen.2005.12.020

[10] Ikemori, R.Y., Machado, C.M., Furuzawa, K.M., Nonogaki, S., Osinaga, E., Umezawa, K., de Carvalho, M.A., Verinaud, L. and Chammas, L. (2014) Galectin-3 Up-Regulation in Hypoxic and Nutrient Deprived Microenvironments Promotes Cell Survival. PLoS ONE, 9, e111592. https://doi.org/10.1371/journal.pone.0111592

[11] Hashmi, S. and Al-Salam, S. (2015) Galectin-3 Is Expressed in the Myocardium Very Early Post Myocardial Infarction. Cardiovascular Pathology, 24, 213-223. https://doi.org/10.1016/j.carpath.2014.12.001

[12] Sharma, U.C., Pokharel, S., van Brakel, T.J., van Berlo, J.H., Cleutjens, J.P., Schroen, B., et al. (2004) Galectin-3 Marks Activated Macrophages in Failure-Prone Hypertrophied Hearts and Contributes to Cardiac Dysfunction. Circulation, 110, 3121-3128. https://doi.org/10.1161/01.CIR.0000147181.65298.4D

[13] de Boer, R.A., Yu, L. and van Veldhuisen, D.J. (2010) Galectin-3 in Cardiac Remodeling and Heart Failure. Current Heart Failure Reports, 7, 1-8. https://doi.org/10.1007/s11897-010-0004-X

[14] Gucuk, I.E., Akin, S.S., Kafes, H., Basyigit, F., Karalok, N. and Guray, Y. (2016) Evaluation of Galectin-3 Levels in Acute Coronary Syndrome. Annales de Cardiologie et d' Angéiologie, 65, 26-30. https://doi.org/10.1016/j.ancard.2015.09.046

[15] Falcone, C., Lucibello, S., Mazzucchelli, I., Bozzini, S., D’Angelo, A., Schirinzi, S., et al. (2011) Galectin-3 Plasma Levels and Coronary Artery Disease: A New Possible Biomarker of Acute Coronary Syndrome. International Journal of Immunopathology and Pharmacology, 24, 905-913. https://doi.org/10.1177/039463201102400409

[16] Menini, S., Iacobini, C., Ricci, C., Blasetti Fantauzzi, C., Salvi, L., Pesce, C.M., et al. (2013) The Galectin-3/RAGE Dyad Modulates Vascular Osteogenesis in Atheroscle-Rosis. Cardiovascular Research, 100, 472-480.

https://doi.org/10.1093/cvr/cvt206

[17] Papaspyridonos, M., McNeill, E., de Bono, J.P., Smith, A., Burnand, K.G., Channon, K.M., et al. (2008) Galectin-3 Is an Amplifier of Inflammation in Atherosclerotic Plaque Progression through Macrophage Activation and Monocyte Chemoattraction. Arteriosclerosis, Thrombosis, and Vascular Biology, 28, 433-440. https://doi.org/10.1161/ATVBAHA.107.159160

[18] Goenka, L., George, M., Singh, V., Jena, A., Seshadri, D., Karunakaran, V., et al. (2017) Do ANGPTL-4 and Galectin-3 Reflect the Severity of Coronary Artery Disease. Therapeutic Advances in Cardiovascular Disease, 11, 261-270. https://doi.org/10.1177/1753944717723311

[19] Szadkowska, R.N., Migała, W.M., Szadkowski, K., Zielińska, M., Paradowski, M., et al. (2013) The Association between Galectin-3 and Clinical Parameters in Patients with First Acute Myocardial Infarction Treated with Primary Percutaneous Coronary Angioplasty. Cardiology Journal, 20, 577-582. https://doi.org/10.5603/CJ.2013.0157

[20] Grandin, E.W., Jarolim, P., Murphy, S.A., Ritterova, L., Cannon, C.P., Braunwald, E., et al. (2012) Galectin-3 and the Development of Heart Failure after Acute Coro- 
nary Syndrome: Pilot Experience from PROVE IT-TIMI 22. Clinical Chemistry, 58, 267-273. https://doi.org/10.1373/clinchem.2011.174359

[21] Tsai, T.H., Sung, P.H., Chang, L.T., Sun, C.K., Yeh, C.K., Chung, S.Y., Chua, S., et al. (2012) Value and Level of Galectin-3 in Acute Myocardial Infarction Patients Undergoing Primary Percutaneous Coronary Inter-Vention. Journal of Atherosclerosis and Thrombosis, 19, 1073-1082. https://doi.org/10.5551/jat.12856

[22] Lisowska, A., Knapp, M., Tycińska, A., Motybel, E., Kamiński, K., Święcki, P., Musiał, W.J. and Dymicka-Piekarska, V. (2016) Predictive Value of Galectin-3 for the Occurrence of Coronary Artery Disease and Prognosis after Myocardial Infarction and Its Association with Carotid IMT Values in These Patients: A Mid-Term Prospective Cohort Study. Atherosclerosis, 246, 309-317.

https://doi.org/10.1016/j.atherosclerosis.2016.01.022

\section{List of Abbreviations}

ACS: Acute coronary syndrome.

STEMI: ST segment elevation myocardial infarction.

NSTEMI: Non ST segment elevation myocardial infarction.

ELISA: Enzyme linked immunosorbent assay.

MI: Myocardial infarction. 